\title{
NEW BDA PRESIDENT INSTALLED
}

At this year's British Dental Conference and Exhibition Dr Janet Clarke became the 125th President of the British Dental Association (BDA). Dr Clarke was presented with her chain of office and made her inaugural speech as BDA President on 19 May at the Manchester Central Convention Complex.

Dr Clarke is Clinical Director of Birmingham Community Healthcare Trust Community Dental Service (CDS), managing an NHS dental budget of over £6 million, and is an Honorary Clinical Lecturer at Birmingham Dental School.

Dr Clarke was awarded her Bachelor of Dental Surgery degree in 1981 and a Master of Community Dental Health in 1989. She has significant experience of representing the dental profession both locally and nationally and successfully led the negotiations

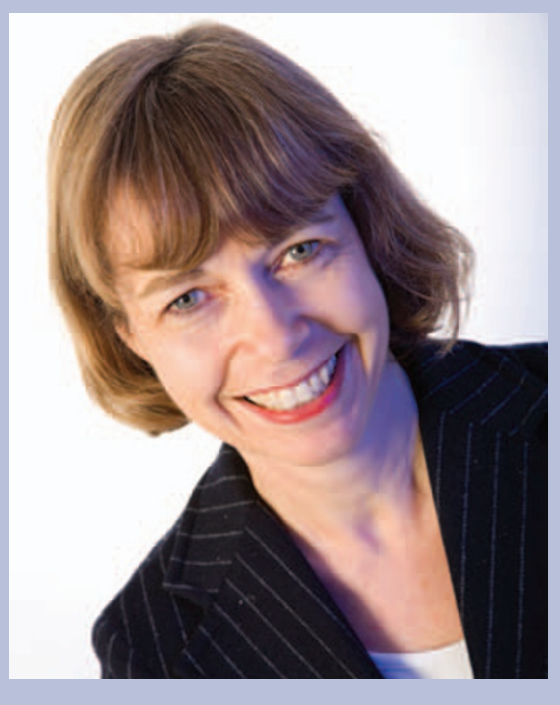

to introduce a new contract for salaried primary care dentists in 2007.

Dr Clarke is married with two children and away from dentistry is fond of shopping and holidays.

\section{BARBADOS CONFERENCE}

A new Commonwealth Dental Association event is currently in preparation about the recognition of abuse in adults and children and how dental professionals may become involved. Supported by the Barbados Dental Association, the event will consist of lectures looking at identifying, treating and referring people suffering abuse to appropriate areas.

The event will be held in Barbados from 23-26 November 2011 at a 4-star hotel on the beach on the Caribbean side of the island. To receive more details about the programme and venue, contact Victor Eastmond at veastmond@caribsurf.com.

\section{ANTIBIOTICS HAVE LIMITED BENEFIT FOR INFECTIVE ENDOCARDITIS PREVENTION}

Researchers from Sheffield have found that a common treatment for infective endocarditis has limited benefit for patient outcomes.

A research team led by Martin Thornhill, Professor of Oral Medicine, assessed the impact of the prescription of antibiotics on the prevention of infective endocarditis prior to invasive dental procedures.

Until 2008 it was common practice in the UK to prescribe antibiotics before such procedures to help prevent the condition, which affects around ten in 100,000 people in the UK annually. However, the National Institute for Health and Clinical Excellence (NICE) published guidance that year which recommends antibiotics are not routinely offered, due to doubts over their effectiveness.

The researchers found that in the two years following the introduction of the guideline, while prescriptions of the antibiotics decreased by $78.6 \%$, there was no significant increase in the number of cases of, or deaths caused by, endocarditis. '[This] does not rule out the possibility that antibiotics may be beneficial for a small group of patients at particularly high risk of developing endocarditis,' commented Professor Thornhill.

The full article is available in the $B M J$ at www.bmj.com/content/342/ bmj.d2392.full. 